\title{
A Self Threshold Voltage Compensated Rectifier for RF Energy Harvesting using 45nm CMOS Technology
}

\author{
CHINMOY BHARALI \\ Department of Electronics and Communication Engineering, \\ Gauhati University Guwahati, INDIA \\ MANASH PRATIM SARMA \\ Department of Electronics and Communication Engineering \\ Gauhati University, Guwahati, INDIA
}

\begin{abstract}
A high frequency rectifier is the core of a RF energy harvesting system. It should offer a very good efficiency at low input power levels and to obtain that compensation of threshold voltage is a very important aspect. A threshold compensation scheme for MOSFETS for RF rectifier applicable in RF energy harvesting system is presented in this paper. The switching of the MOSFET is improved with overall enhancement of output rise time of the system. The design emphasis is to have a simplified circuit without the requirement of any external source so as to achieve self-sustainability in the true sense. The rectifier circuit is derived from the basic Dickson charge pump model and is evaluated using $45 \mathrm{~nm}$ CMOS process. The design has utilized Metal Oxide Semiconductor Field Effect Transistor instead of basic diodes which ensures low power along with fabrication feasibility. The maximum measured PCE of the design is obtained to be $33 \%$ at $4 \mathrm{dBm}$ input power level at $500 \mathrm{Mhz}$ frequency with 1 Kilo Ohm load resistance. The output transient response rise time has been measured to be $85 \mathrm{~ns}$ at $500 \mathrm{MHz}$ and $50.10 \mathrm{~ns}$ at $1 \mathrm{Ghz}$.
\end{abstract}

Keywords-Power Conversion Efficiency, Peak to Peak Voltage, Dickson Charge Pump, Threshold Value. Received: March 24, 2021. Revised: July 18, 2021. Accepted: August 2, 2021. Published: August 10, 2021.

\section{Introduction}

Radio frequency (RF) energy harvesting is becoming a very important research area in the advent of green communication. The basic idea of implementation of RF energy harvesting system is to avoid external batteries or connection to any other power source $[1,2,3]$. This makes the communication nodes self-sustainable in terms of power and eliminates the difficulties in remote locations. Among all other renewable sources RF energy harvesting is a promising candidate with advantages of flexibility and portability. The RF energy harvesting system consists of a receiving antenna, a RF rectifier to convert the RF energy into DC energy and a power management unit to manage the harvested power. This is shown in figure 1 . The output DC energy can be used by any load or can be stored in capacitors or external batteries. With the advancement of communication, along with faster and reliable data transfer mechanisms, energy management and conservations are getting more attention and is becoming a major and indispensable part of communication research. As selfsustainability to communication nodes is a very important aspect, RF energy harvesting must play a powerful role.

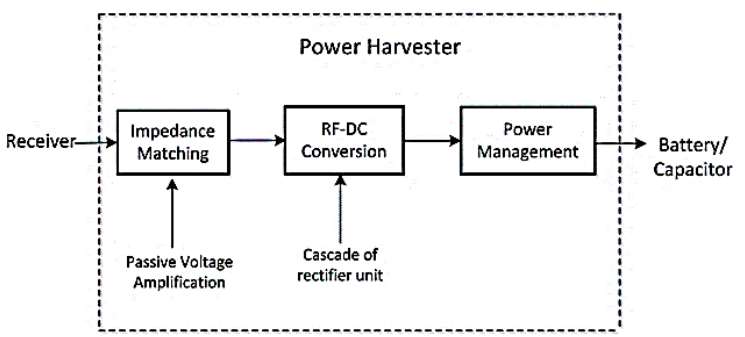

Figure 1: Block diagram of a RF energy harvesting system
The overall performance of the RF energy harvesting system is based on the sensitivity and the overall efficiency. The rectifier circuit is one of the main blocks that is responsible for determining the overall performance of an RF harvesting system. Recently, there has been an increased demand for highly-sensitive and highly-efficient rectifier circuits. Rectifier's sensitivity is defined as the lower limit input power level at which the rectifier is able to operate. The efficiency of a rectifier circuit indicates how well the rectifier is capable of converting the received RF power into $\mathrm{dc}$ power along with self-loss of power in the rectifier.

Design of a reconfigurable rectifier will also give a wide PCE response for a wide input power range. Gradually increasing the efficiency of the RF EH system. In this paper, the design of a reconfigurable rectifier with circuit-based solution for threshold reduction of the devices is implemented. The maximum measured PCE of the design is obtained to be $33 \%$ at $4 \mathrm{dBm}$ input power level at $500 \mathrm{MHz}$ frequency with 1 Kilo Ohm load resistance. The output transient response rise time has been measured to be $85 \mathrm{~ns}$ at $500 \mathrm{MHz}$ and $50.10 \mathrm{~ns}$ at $1 \mathrm{Ghz}$.Further details of the theory, design, and experimental results for the circuit are given in following sections.

\section{Proposed Design}

\subsection{The Charge Pump}

The rectifier plays a signification role in the RFEH system. So, the prime objective of this work is to develop a rectifier with faster response time that is to develop certain technique for effective threshold compensation and better conversion efficiency. Fig. 2 shows the circuit schematic of a single stage Dickson charge pump. In order to find the optimum device sizes a single stage Dickson charge pump [10] was examined. 


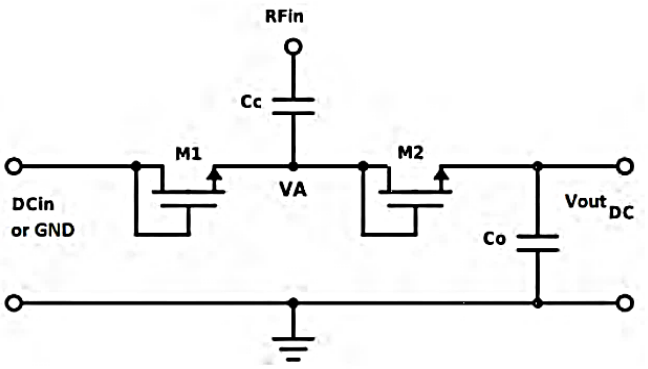

Figure 2: Dickson Charge Pump

A single-stage Dickson charge pump rectifier consists of two NMOS transistors, M1 and M2, one coupling capacitor $(\mathrm{Cc})$, and one multiplying/output capacitor (Co). The RF signal is applied to RF input terminal. The DC input node is connected to an external DC supply or it is grounded as per requirement. The RF-to-DC conversion in the charge pump is during the first negative half cycle (as $\mathrm{V}_{\mathrm{RF}}<\mathrm{V}_{\mathrm{TH}}$ ), turns on $\mathrm{M} 1$ and $\mathrm{Cc}$ charges until the voltage across its nodes is equal to the amplitude of the RF input signal and As the RF input reaches its positive half cycle (where $\mathrm{VRF}>\mathrm{VTH}$ ). M2 turns on allowing Co to charge through the input RF signal and through the $\mathrm{Cc}$. The charged $\mathrm{Cc}$ gets discharged into $\mathrm{Co}$. At this point, the potential of VA is

$$
\mathrm{V}_{\mathrm{A}}=2 \mathrm{~V}_{\mathrm{RF}}-\mathrm{V}_{\mathrm{TH}}
$$

where VRF is the amplitude of input signal and the output voltage is

$$
\text { Vout }=2\left(\mathrm{~V}_{\mathrm{RF}}-\mathrm{V}_{\mathrm{TH}}\right)
$$

From equation (1) and (2), it is observed that the threshold voltage of the used transistors (VTH) plays a very important role in the value of the output voltage. Hence, lower the threshold voltage of transistors is, the higher is the magnitude of the output voltage.

\subsection{The Proposed Rectifier}

Fig. 3 shows the proposed threshold compensated rectifier constructed by cascading a comparator circuit with a Dickson charge pump. The positive terminal of the comparator has an input feedback from the output of the Dickson charge pump. The output of the comparator circuit is providing the bias voltage to the M1 device of the Dickson charge pump.

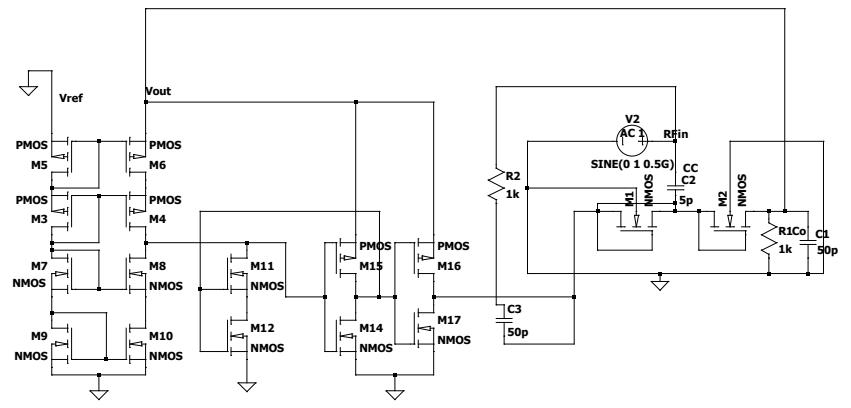

Figure 3: Proposed Rectifier Circuit

The comparator circuit provides an in phase bias voltage with respect to the RF input signal to the M1 device of the charge pump. This in phase bias voltage always remains in the positive phase which results in providing a alternating bias voltage to trigger the M1 device of the charge pump.

\section{Experiment Results}

\subsection{Comparator output voltage}

In Fig. 4 the output voltage waveform of the comparator circuit with reference to RF input signal is shown is shown. $\mathrm{V}(\mathrm{n} 006)$ is the output of the comparator and $\mathrm{V}(\mathrm{n} 002)$ is the input RF signal.

It is observed from the figure above that the comparator provides a phase bias voltage at similar phase as that of input RF signal. This output of the comparator is providing a bias voltage of average value $742.18 \mathrm{mV}$ to the drain gate node of M1 device.

For the conditioning of the comparator output signal the RC circuit is implemented in the circuit. The comparator is grounded in its inverted terminal and the non-inverting terminal is an input of the looped back voltage of the output of the Dickson charge pump.

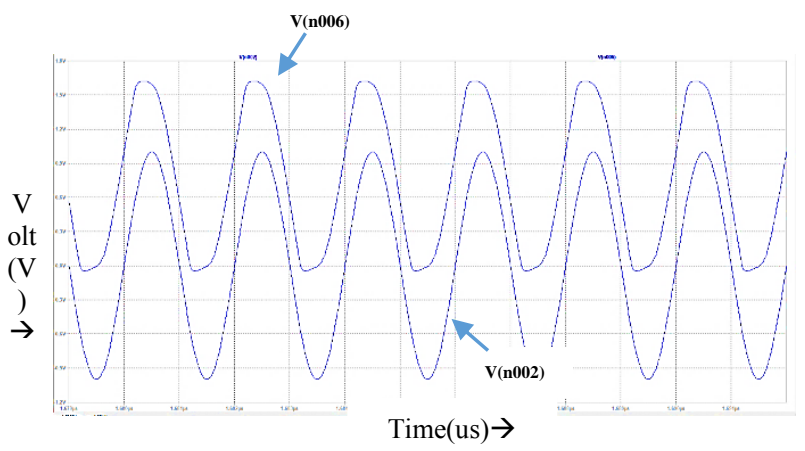

Figure 4: Waveform of the output of the comparator and the input RF signal

The output signal cannot be directly feedback to the M1 device because if it is done there will be more negative node voltage and leakage current will develop at M1 drain node. The comparator serves a more positive output voltage which serves its purpose of pre biasing the device near its threshold region. So, at even lower magnitude voltage of the input RF signal M1 gets into saturation region. It is observed that the output of the comparator gives a higher peek to peek voltage then the RF input signal this is due to internal gain of the comparator. The output current of the comparator is $2.3028 \mathrm{~mA}$ RMS value.

The manually set Vth of the device is $429 \mathrm{mv}$. In the traditional Dickson charge pump the RF signal has to reach this value to make the device on. But now when the comparator output voltage reaches $721 \mathrm{~m} \mathrm{~V}$ the RF signal value is at this point of time is approx. $-287.12301 \mathrm{mV}$. Therefore, at this point the overall voltage is more than the threshold voltage. The device will remain in on state until the RF input value reaches $-75.65 \mathrm{mV}$. Hence the device is on much faster than in the traditional configuration. This enhances the switching time and on state duration of the device. 


\section{2 Rectifier parameter analysis}

The first parameter that needed to be selected was the device length Fig. 5 shows the output voltage variation when the transistor length is varied from $65 \mathrm{~nm}$ to $500 \mathrm{~nm}$.

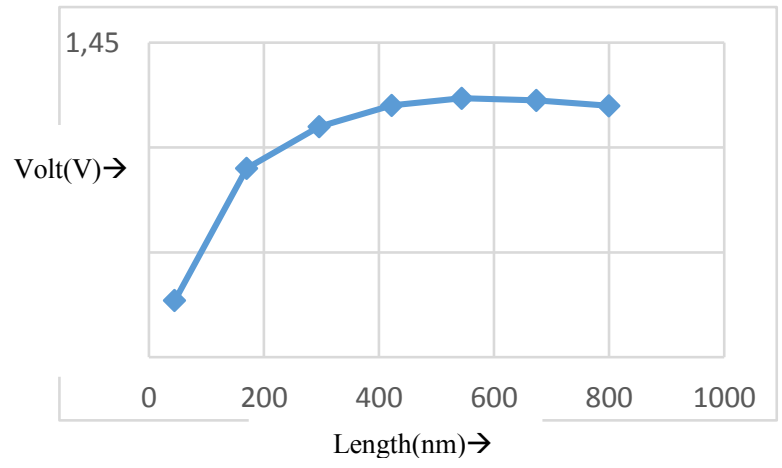

Figure 5: Simulated output voltage variation versus channel length

It is observed that after $500 \mathrm{~nm}$ the output voltage of the rectifier starts to degrade. The second parameter to be examined is the transistor width. Fig. 6 shows the alterations in output voltage when channel width is swept from $65 \mathrm{~nm}$ to $2000 \mathrm{~nm}$.

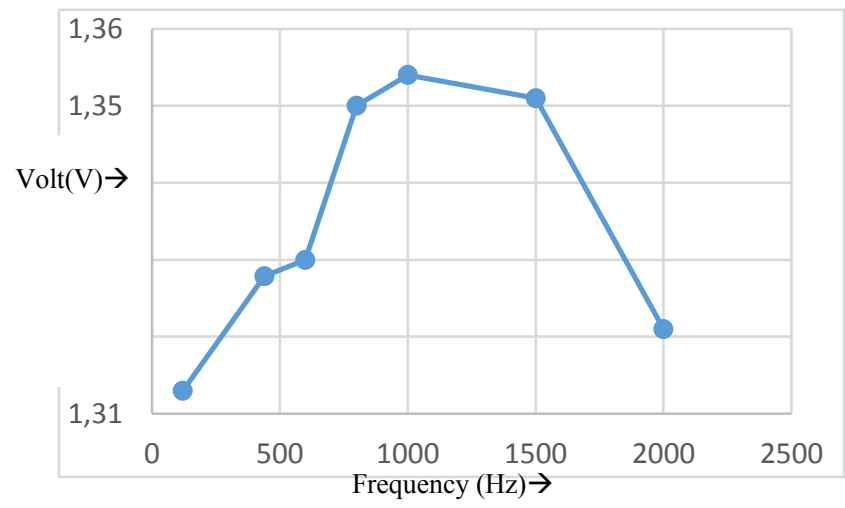

Figure 6: Simulated output voltage variation versus channel width

So, it is clear from the graph that after $1000 \mathrm{~nm}$ the output voltage of the rectifier starts to degrade. From these two figures the aspect ratio of the devices was chosen.

Initially the operating frequency band of the proposed design is analyzed in the simulation platform. The RF source frequency here is swept in the RF range $20 \mathrm{Khz}$ to $300 \mathrm{Ghz}$. The magnitude and phase plot of the frequency sweep is given in the Fig. 8 below.

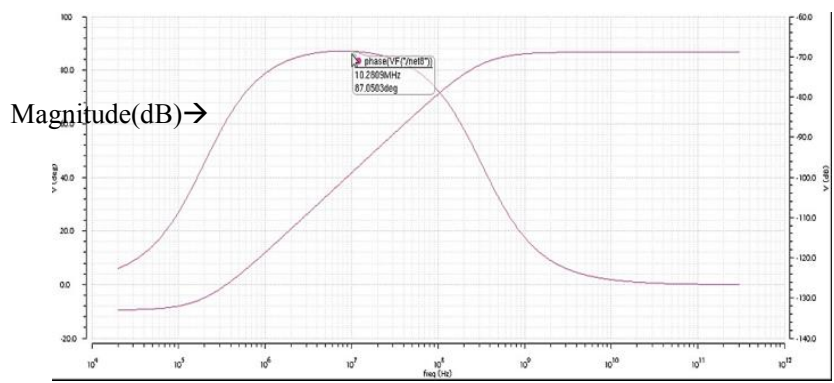

Figure 8: Magnitude vs Phase plot

As a result, it is observed that the gain of the rectifier remains constant after $1 \mathrm{GHz}$ so we choose the operating frequency range for the circuit to be between $200 \mathrm{MHz}$ to $1 \mathrm{GHz}$.

The load resistance of the rectifier is swept from 500 ohms to $100 \mathrm{~K}$ ohms. The graph in the Fig. 9 below shows different varying parameters of the circuit with variation of the load resistance.

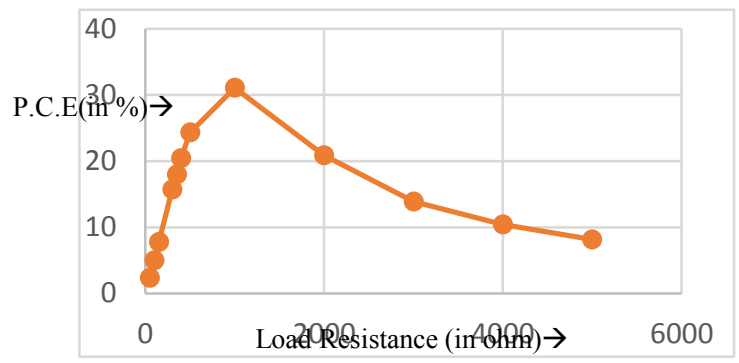

Figure 9: RL vs PCE graph

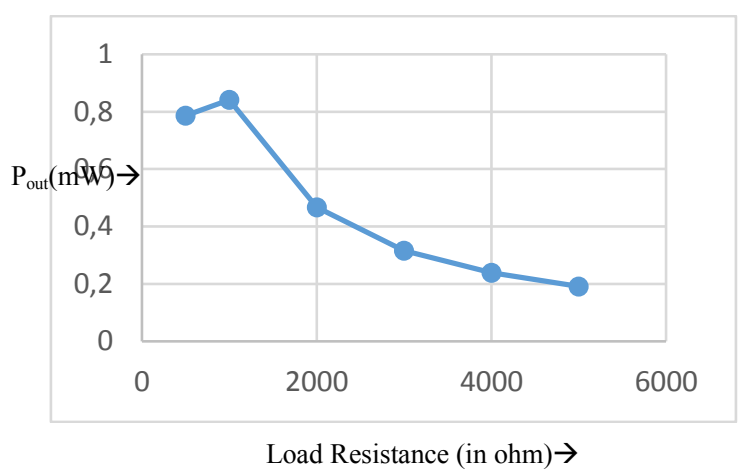

Figure 10: RL vs $P_{\text {out }}$ graph

Fig 10. shows the Load Resistance vs Output Power graph. Here it is observed that at 1 Kilo ohm load resistor value maximum power is delivered to the load. The calculated input power at this value is $4.09 \mathrm{dBm}$.

\subsection{MOSFET Output Rise Time}

Turn on time $\mathrm{t}_{\mathrm{on}}=\mathrm{t}_{\mathrm{d}}$ (on) $+\operatorname{tr}$ (Rise time)

It is clear from the above equation that if the rise time $\left(t_{r}\right)$ of the MOSFET is increase then the turn on time of the device also increases. So, the rise time for the conventional Dickson Charge pump is tr $=98.6309607 \mathrm{~ns}$

But, in the proposed circuit the turn on time at $500 \mathrm{MHz}$ and $1 \mathrm{GHz}$ operating frequency is $85.055859 \mathrm{~ns}$ and $50.10 \mathrm{~ns}$ approx.

The plot for the rise time from $100 \mathrm{MHz}$ to $1 \mathrm{GHz}$ is shown in Fig. 11 below 


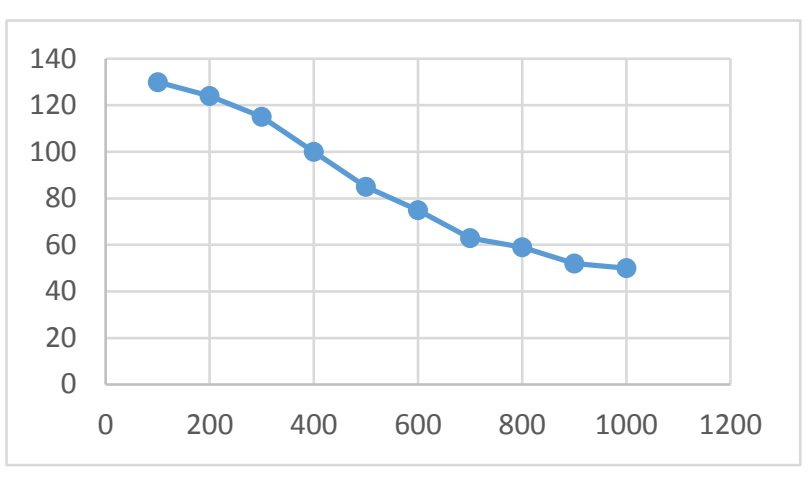

Figure 11: Frequency vs Rise time plot

It is observed from the above graph that the rise time keeps degrading when the Frequency is higher. At $500 \mathrm{MHz}$ the PCE of the rectifier calculated is $33 \%$ at $4 \mathrm{dBm}$ input power and at the $1000 \mathrm{MHz}$ the PCE farther degrades to $26 \%$ at $5.7 \mathrm{dBm}$ input power. Farther increasing the operating frequency, the rise time will certainly fall which is desired but at the cost of PCE degradation.

The Optimized parameters of the proposed rectifier is shown in Table I below.

Freauencv $(\mathrm{MHz}) \rightarrow$

TABLE I. Optimized parameters of the proposed rectifier

\begin{tabular}{|c|c|}
\hline Parameter & Optimized Value \\
\hline $\begin{array}{c}\text { MOSFET } \\
\text { Channel Length }\end{array}$ & $45 \mathrm{~nm}$ \\
\hline $\begin{array}{c}\text { MOSFET } \\
\text { Channel Width }\end{array}$ & $120 \mathrm{~nm}$ \\
\hline Operating Frequency & $200 \mathrm{MHz}$ to $1 \mathrm{GHz}$ \\
\hline Load Resistance & $1 \mathrm{kilo} \mathrm{ohm}$ \\
\hline PCE & $33 \%$ Max) \\
\hline M1 Device Turn on voltage & $-287.12301 \mathrm{mV}$ \\
\hline Comparator output current & $2.3028 \mathrm{~mA}(\mathrm{RMS})$ \\
\hline Coupling Capacitor $(\mathrm{CC})$ & $5 \mathrm{pf}$ \\
\hline Output Capacitor (Cout) & $70 \mathrm{pf}$ \\
\hline Output Rise time (tr) & $85 \mathrm{~ns}$ at $500 \mathrm{MHz}$ to $50 \mathrm{~ns}$ at \\
& $1 \mathrm{GHz}$ \\
\hline
\end{tabular}

Hence, it is observed that the threshold voltage to trigger the M1 device of the charge pump is lowered from 400mv to $287.1 \mathrm{mV}$ and the turn on period of the device is also increased.

Table II summarizes the various threshold level compensated

rectifiers parameters for $\mathrm{RF}$ energy harvesting. It can be seen that our proposed rectifier achieves peak $33 \%$ efficiency at $4 \mathrm{dBm}$ input power and achieves an output rise time of $85.055859 \mathrm{~ns}$ at $500 \mathrm{MHz}$ and efficiency of $26 \%$ at $5.7 \mathrm{dBm}$ input power and achieves output rise time of $50 \mathrm{~ns}$ at $1 \mathrm{GHz}$. Compared to other designs the proposed rectifier achieves better efficiency and certainly lowered threshold value for better switching of MOSFET operating regions.
TABLE II.

Performance Comparison with other Reported Works

\begin{tabular}{|c|c|c|c|c|c|c|}
\hline $\begin{array}{l}\text { Technolo } \\
\text { gy }\end{array}$ & $\begin{array}{l}\text { Referen } \\
\text { ce }\end{array}$ & $\begin{array}{l}\text { Frequen } \\
\text { cy }\end{array}$ & $\begin{array}{l}\text { Input } \\
\text { Power } \\
\text { (dBm) }\end{array}$ & $\begin{array}{l}\text { Outpu } \\
\text { t } \\
\text { Voltag } \\
\mathrm{e}\end{array}$ & $\begin{array}{l}\text { Loa } \\
\text { d } \\
\text { (K } \\
\text { ohm } \\
\text { ) }\end{array}$ & $\begin{array}{l}\text { PCE } \\
(\max \\
)\end{array}$ \\
\hline $\begin{array}{l}\text { nm } \\
\text { CMOS }\end{array}$ & $\begin{array}{l}\text { Single } \\
\text { Stage } \\
\text { Dickson }\end{array}$ & 500 & -11.39 & $\begin{array}{l}201.2 \\
\mathrm{mv}\end{array}$ & 10 & $\begin{array}{l}11.25 \\
\%\end{array}$ \\
\hline $\begin{array}{c}180 \\
\mathrm{~nm} \mathrm{Cmos}\end{array}$ & [7] & 433 & -5 to -9 & -- & 10 & $\begin{array}{l}22 \% \\
\text { to } 30 \\
\%\end{array}$ \\
\hline $\begin{array}{l}130 \\
\mathrm{~nm} \\
\text { CMOS }\end{array}$ & [8] & -- & -15 & $1 \mathrm{v}$ & $\begin{array}{l}100 \\
0\end{array}$ & $32 \%$ \\
\hline $\begin{array}{l}\mathrm{nm}^{65} \\
\mathrm{CMOS}\end{array}$ & [9] & $\begin{array}{l}900 \mathrm{MHz} \\
\text { and } \\
2.4 \mathrm{GHz}\end{array}$ & -18 & $1 \mathrm{v}$ & $\begin{array}{l}100 \\
0\end{array}$ & $\begin{array}{l}16.8 \\
\%\end{array}$ \\
\hline $\begin{array}{l}\quad 45 \\
\text { nm } \\
\text { CMOS }\end{array}$ & $\begin{array}{l}\text { This } \\
\text { Work }\end{array}$ & $500 \mathrm{MHz}$ & 4 & $\begin{array}{l}916.69 \\
8 m v\end{array}$ & 1 & $33 \%$ \\
\hline
\end{tabular}

\section{Conclusion}

The design is implemented using $45 \mathrm{~nm}$ CMOS process. The threshold compensation is achieved by a scheme that completely removes the requirement of any other external source and thereby making it fully self-sustainable. The proposed design has attained a PCE of $33 \%$ at $4 \mathrm{dBm}$ input power and $26 \%$ at $5.7 \mathrm{dBm}$ input power at $10 \mathrm{~K}$ ohm load resistance. The design gives a better magnitude gain after 1 $\mathrm{GHz}$ which leads to better sensitivity at low input power levels. The average output voltage at $500 \mathrm{MHz}$ input is $916.698 \mathrm{mv}$ and at $1 \mathrm{GHz}$ the average output voltage is $992 \mathrm{mv}$. The aspect ratio of the devices is $3 / 8$. The output rise time is measured to be $85.055859 \mathrm{~ns}$ at $500 \mathrm{MHz}$ and $50.10 \mathrm{~ns}$ at $1 \mathrm{GHz}$. This validates the suitability of the circuit in RF frequencies with an acceptable PCE and faster response.

\section{References.}

[1] Danial Khan, Seong Jin Oh, Khuram Shehzad, Deeksha Verma, Young Gun Pu, Minjae Lee, Cheol Hwang, Youngoo Yang, And Kang-Yoon Lee "An Efficient Reconfigurable RF-DC Converter with wide Input Power Range for RF Energy Harvesting" IEEE Access ,Volume: 8, pp- 79310-79318, 2020

[2] Mohamed A. Abouzied, Krishnan Ravichandran And Edgar Sánchez-Sinencio Life Fellow, IEEE "A Fully Integrated Reconfigurable Self-Startup RF EnergyHarvesting System With Storage Capability" IEEE journal of solid-state circuits, Volume: 52 , Issue: 3 , pp704-719, March 2017

[3] Soroush Dehghani, Student member IEEE Shahriar Mirabbasi And Thomas Johnson, member IEEE “A 5.8$\mathrm{GHz}$ Bidirectional and Reconfigurable RF Energy, Harvesting Circuit withRectifier and Oscillator Modes" IEEE Solid-State Circuits Letters Volume: 1, Issue: 3,pp-6669, March 2018 
[4] XING LI, CHI-YING TSUI, AND WING-HUNG KI "UHF Energy Harvesting System using Reconfigurable Rectifier for Wireless Sensor Network" IEEE International Symposium on Circuits and Systems (ISCAS), 2015, Lisbon

[5] Zizhen Zeng, Xing Li, Amine Bermak, Chi-Ying Tsui And Wing-Hung Ki "A Wlan 2.4-GHz RF Energy

Harvesting System with Reconfigurable Rectifier for Wireless Sensor Network" IEEE International Symposium on Circuits and Systems (ISCAS), 2016, Canada

[6] Zizhen Zeng, Johan J. Estrada-López, Mohamed A.Abouzied, And Edgar Sánchez-Sinencio "A ReconfigurableRectifier with Optimal Loading Point Determination for RF Energy Harvesting from $-22 \mathrm{dBm}$ to $-2 \mathrm{dBmIEEE}$ Transactions on Circuits and Systems II: Express Briefs, Volume: 67, Issue: 1, pp-87-91, Jan. 2020

[7] S.S. Chouhan and K. Halonen, "Threshold voltage compensation scheme for RF-to-DC converter used in RFID applications" DOI:10.1049/el.2015.0445

[8] Z. Hameed and K. Moez, "A 3.2 V -15 dBm Adaptive Threshold-Voltage Compensated RF Energy Harvester in $130 \mathrm{~nm}$ CMOS" IEEE Transactions on Circuits and Systems I: Regular Papers, Volume: 62, Issue: 4, pp948-956, April 2015

[9] Lianxi Liu, Wenzhi Yuan, Junchao $\mathrm{Mu}, \mathrm{Zhu}$, and Yintang Yang, "A Dual Band RF Energy Harvester with Hybrid Threshold Voltage Self-Compensation" Vol. 25, No. 06, 1650055 (2016)

[10] Mansour Taghadosi, Lutfi Albasha , Nasir A. Quadir, Yousuf Abo Rahama, Harshal Chapade, Rajesh Zel And Nasser Qaddoumi "High Efficiency Energy Harvesters in $65 \mathrm{~nm}$ CMOS Process for Autonomous IoT Sensor Applications" IEEE Access ( Volume: 6), pp- $2397-2409,2017$

[11] Harshal Chapade, Rajesh Zel "On-chip RF to DC Power Converter for Bio-Medical Application" 32nd International Conference on VLSI Design and 2019 18th International Conference on Embedded Systems (VLSID), 2019, Delhi, India

[12] Mohamed M. Mansour and H. Kanaya ."High-Efficient Broadband CPW RF Rectifier forWireless Energy Harvesting" DOI: 10.1109/LMWC.2019.2902461

[13] Sajjad Shieh and Mahmoud Kamarei,"Transient Input Impedance Modeling of Rectifiers for RF Energy Harvesting Applications" IEEE Transactions on Circuits and Systems II: Express Briefs, Volume: 65, Issue: 3, pp-311-315,March 2018

[14] Ju Ren, Junying Hu, Deyu Zhang, Hui Guo, Yaoxue Zhang, and Xuemin (Sherman) Shen "RF Energy Harvesting and Transfer in Cognitive Radio Sensor Networks: Opportunities and Challenges" IEEE Communications Magazine, Volume: 56, Issue: 1, pp104-110, Jan. 2018

\section{Creative Commons Attribution License 4.0 (Attribution 4.0 International, CC BY 4.0)}

This article is published under the terms of the Creative Commons Attribution License 4.0 https://creativecommons.org/licenses/by/4.0/deed.en US 